\title{
EFFECT OF ALLOYING ON ION-BOMBARDMENT-INDUCED SURFACE TOPOGRAPHY ON FACE-CENTRED CUBIC METALS
}

\author{
L. CLAPHAM ${ }^{\text {1) }}$, J.L. WHITTON ${ }^{\text {1) }}$, A. MASHAYEKHI ${ }^{2)}$, G. CARTER ${ }^{\text {3) }}$, I. KATARDJIEV ${ }^{3)}$ \\ and M.J. NOBES ${ }^{3)}$ \\ ${ }^{1)}$ Queen's University, Kingston, Ontario, Canada \\ 2) Michigan Ion Beam Laboratory, Ann Arbor, Michigan, USA \\ 3) University of Salford, Salford, UK
}

Previous studies of sputter-induced topographical development have shown that it is possible to form pyramids on single-crystal fcc metals oriented in the $\langle 1131\rangle$ crystallographic direction. These pyramids form when the surface is bombarded with relatively large $\left(>1 \times 10^{19} \mathrm{~cm}^{-2}\right.$ ) doses of $\mathrm{Ar}^{+}, \mathrm{Kr}^{+}$or $\mathrm{Xe}^{+}$ions in the energy range $20-41 \mathrm{keV}$. Until recently most of the work was confined to pure $\mathrm{fcc}$ metals ( $\mathrm{Cu}, \mathrm{Pd}, \mathrm{Ir}, \mathrm{Ag}, \mathrm{Au}$ ), all of which exhibit similar pyramid formation on bombardment. Later studies involving $\langle 1131\rangle \mathrm{Cu}$, however, showed that, although pyramids form with inert-gas ion (e.g. $\mathrm{Ar}^{+}$on $\mathrm{Cu}$ ) or self-ion (Cu${ }^{+}$on $\mathrm{Cu}$ ) bombardment, they are not produced when either $\mathrm{Br}^{+}, \mathrm{Fe}^{+}$or $\mathrm{Ni}^{+}$ions are used. This observation led to further investigations of alloying effects on topographic evolvement during sputtering. We report here a study of the influence of alloying on pyramid formation on $\langle 1131\rangle$ single crystals, through comparison of that of $\mathrm{Ni}$ and $\mathrm{Cu}$ with that of $\mathrm{Ni}-8 \% \mathrm{Cu}$. We find that bombardment with $\mathrm{Ar}^{+}$ions can produce pyramids on $\mathrm{Ni}-8 \% \mathrm{Cu}$ but that the conditions necessary are different from those for pure metals. We have looked for sputter-induced segregation effects in the alloy but none have been observed.

\section{Introduction}

Our studies over more than a decade have concentrated on the production of well-defined, reproducible features on, mainly, argon-ion-bombarded singlecrystal copper. References outlining these and related studies are listed as refs. [1-10].

It is clearly established that pyramidal features can be reproducibly formed on copper of $\langle 1131\rangle$ orientation. The bombardment parameters required to produce these pyramids, which have been shown to have octagonal bases, are:

$\begin{array}{ll}\text { incident energy } & 20-41 \mathrm{keV} ; \\ \text { ion dose } & 5 \times 10^{18-2} \times 10^{19} \\ & \text { ions } / \mathrm{cm}^{2} ; \\ \text { dose rate } & 100-500 \mu \mathrm{A} / \mathrm{cm}^{2} ; \\ \text { target temperature } & 80-550 \mathrm{~K} ; \\ \text { target chamber pressure } & 7 \times 10^{-3}-5 \times 10^{-7}\end{array}$

$\mathrm{Pa}$.

Within these parameters the most important condition for pyramid production is that of crystal orientation, i.e., unless the crystal face has the $\langle 1131\rangle$ orientation, pyramids will not be formed. Conical features may be produced in other orientations but they require that impurities be present. We take care, in all our studies, to ensure that the crystal faces are free of impurities and, as far as possible, of defects, before the ion bombardment.

Further to the $\mathrm{Ar}^{+}$on $\mathrm{Cu}$ case, we extended our

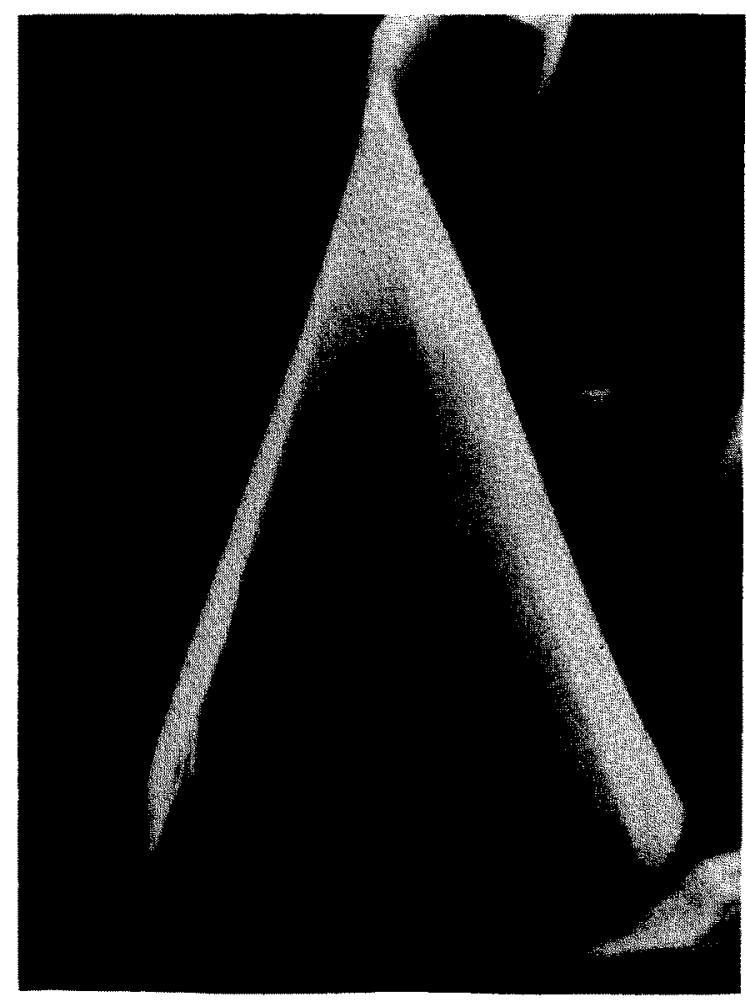

Fig. 1. Scanning electron micrograph of an octagonal pyramid on an 〈1131) surface of $\mathrm{Ni}-8 \% \mathrm{Cu}$ after bombardment with $40 \mathrm{keV} \mathrm{Ar}^{+}$to $2 \times 10^{19}$ ions $/ \mathrm{cm}^{2}$. Magnification $1500 \times$. 
studies [11] to include the bombarding ions $\mathrm{Ne}^{+}, \mathrm{Kr}^{+}$, $\mathrm{Xe}^{+}$and the self-ion $\mathrm{Cu}^{+}$. In these cases, with the exception of $\mathrm{Ne}^{+}$, beautifully formed pits and pyramids were produced on the $\langle 1131\rangle$ surface. A further extension was by the argon ion bombardment of $\langle 1131\rangle$ nickel, palladium, silver, irridium and gold, all of which
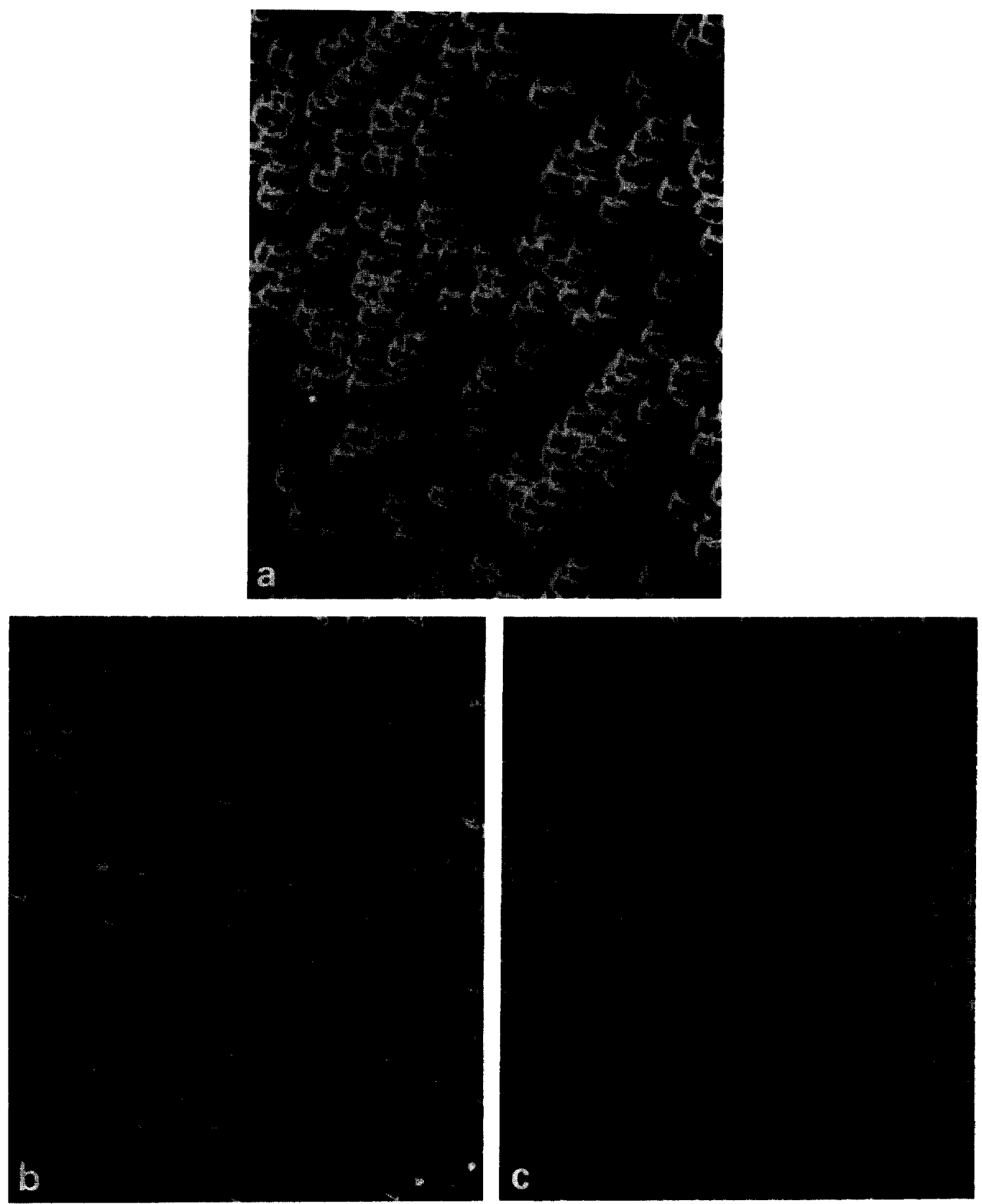

Fig. 2. Scanning electron micrographs of (a) copper, (b) nickel and (c) Ni-8\% Cu $\langle 1131\rangle$ surfaces after bombardment with $40 \mathrm{keV}$ $\mathrm{Ar}^{+}$to $2 \times 10^{19}$ ions $/ \mathrm{cm}^{2}$. Magnification $200 \times$. 
resulted in the production of pits and pyramids. At this point it appeared that these features could be quite routinely produced.

However, since all of these effects can be ascribed to purely ballistic mechanisms, more recent work made use of bombarding ions of $\mathrm{Fe}^{+}, \mathrm{Ni}^{+}$and $\mathrm{Br}^{+}$into $\langle 1131\rangle$ $\mathrm{Cu}$ [12]. The reasoning was that while the inert-gas ions and the self-ion copper should result in purely ballistic processes, the same might not be true for ions of similar mass which could have chemical or metallurgical effects on the copper matrix. This turned out to be the case since, while sputter-etch pits were formed with all three ion types, no pyramids (with the exception of very isolated single pyramids due to $\mathrm{Ni}^{+}$bombardment) were produced.

It should be noted that the copper matrix can play no part in this change from the normally obtained results since, if any of the $\mathrm{Fe}^{+}, \mathrm{Ni}^{+}$or $\mathrm{Br}^{+}$bombardments (which produced essentially no pyramidal features) were followed by a $\mathrm{Kr}^{+}$bombardment, the normally expected pits and pyramids appeared. Conversely, a $\mathrm{Kr}^{+}$bombardment which produced pyramids had these eliminated when followed by bombardments with any of the other three species. One possible explanation of this behaviour is that the bombardment with other than self-ion or inert gases could lead to the formation of an alloyed component no matter the purity of the original matrix. Preferential sputtering of one of the components could then prevent any tendency to form pyramidal features.

\section{Results and discussion}

A preliminary investigation [13] of this possibility was made with the $\mathrm{Ar}^{+}$ion bombardment of an $\langle 1131\rangle$ single crystal of a $\mathrm{Ni}-8 \% \mathrm{Cu}$ alloy. The dose level of $1 \times 10^{19}$ ions $/ \mathrm{cm}^{2}$ is, as pointed out earlier, sufficient to produce pyramids on an $\langle 1131\rangle$ nickel crystal. Only etch pits were observed on the alloy surface. This bombardment was made at a dose rate of $60 \mu \mathrm{A} / \mathrm{cm}^{2}$, somewhat lower than the rate criterion, so a repeat was done at $150 \mu \mathrm{A} / \mathrm{cm}^{2}$. This resulted in an increase in pit size with some pyramid formation. Energy-dispersive $\mathrm{X}$-ray spectroscopy (EDS) was used to check the composition of the pitted and nonpitted areas: they were identical (within the experimental error limits of \pm 0.5 wt.\%), thus eliminating the possibility of significant segregation-induced pitting.

Further experiments were made on $\mathrm{Ar}^{+}$ion bombarded $\langle 1131\rangle \mathrm{Ni}-8 \% \mathrm{Cu}, \mathrm{Ni}$ and $\mathrm{Cu}$, again at 60 $\mu \mathrm{A} / \mathrm{cm}^{2}$ to a dose level of $2 \times 10^{19}$ ions $/ \mathrm{cm}^{2}$. On this occasion only etch pits were found on the $\mathrm{Ni}$ and $\mathrm{Cu}$ but both etch pits and pyramids on the alloy. Based on the parameters outlined earlier, one would expect the absence of pyramids on $\mathrm{Ni}$ and $\mathrm{Cu}$ but the surprise is

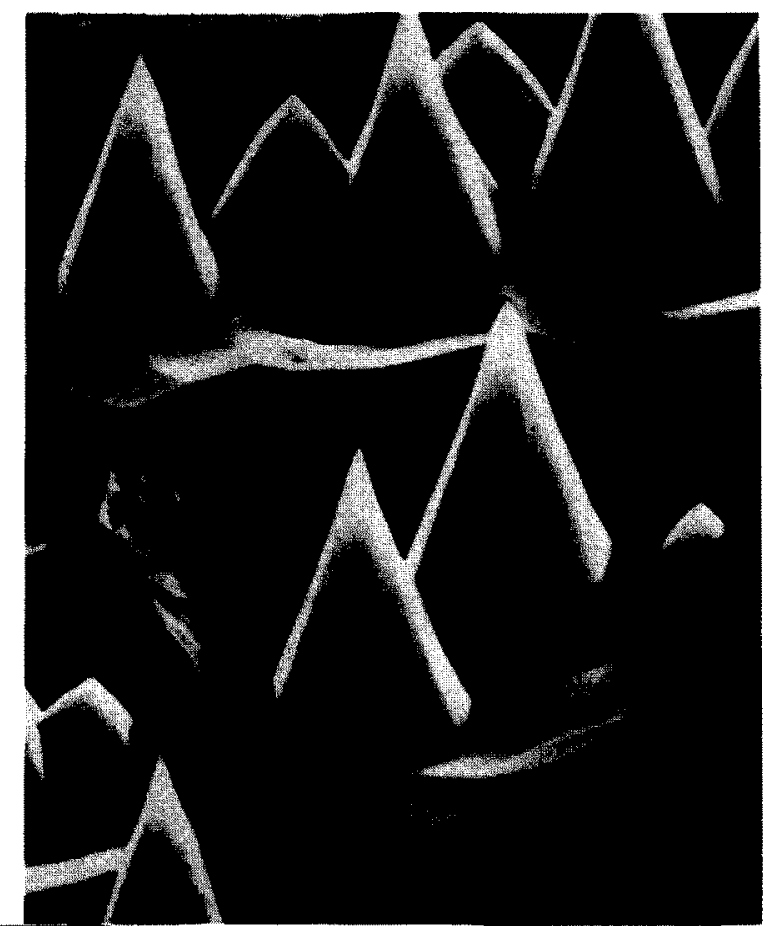

Fig. 3. Scanning electron micrograph of an $\langle 1131\rangle \mathrm{Ni}-8 \% \mathrm{Cu}$ alloy after bombardment with $40 \mathrm{keV} \mathrm{Ar}^{+}$to $2 \times 10^{19}$ ions $/ \mathrm{cm}^{2}$ showing how the octagonal pyramids originate in the centre of the pits. Magnification $6000 \times$

the plethora of pyramids on the alloy. Fig. 1 shows that the pyramidal features on the alloy are identical to those always seen on fcc pure metals bombarded at higher dose rates, i.e. with octagonal, slightly tilted base. Earlier detailed crystallographic studies on the $\mathrm{Ar}^{+}-\mathrm{Cu}$ system showed that the pyramid base was tilted from the original $\langle 1131\rangle$ surface to accommodate to the $\langle 100\rangle$ base of the sputter-etch pits, although, as shown in fig. 2, the etch pit habits of all three materials are quite different. This is somewhat surprising as the $\mathrm{Cu}$ pyramid facets were shown to lie in the 100 and 110 crystallographic zones which further accommodate the directions of the pit edges. A major difference between the pyramids formed on the alloy at the low dose rate and on the copper at the higher dose rates is that pyramids evolve only seldom from the centre of a pit in the copper case (usually forming by being cut from edges) while the alloy pyramids invariably form at the centre of the pits (see fig. 3). The reason for the production of pyramids at low dose rates on the alloy and not on the pure metals is not clear, although several possibilities have been and are being considered.

For comparison purposes, a high dose rate was then used on all three freshly prepared specimens. In this case the ion energy was $40 \mathrm{keV}$, total dose $1 \times 10^{19}$ ions $/ \mathrm{cm}^{2}$ and dose rate $>500 \mu \mathrm{A} / \mathrm{cm}^{2}$. These results 

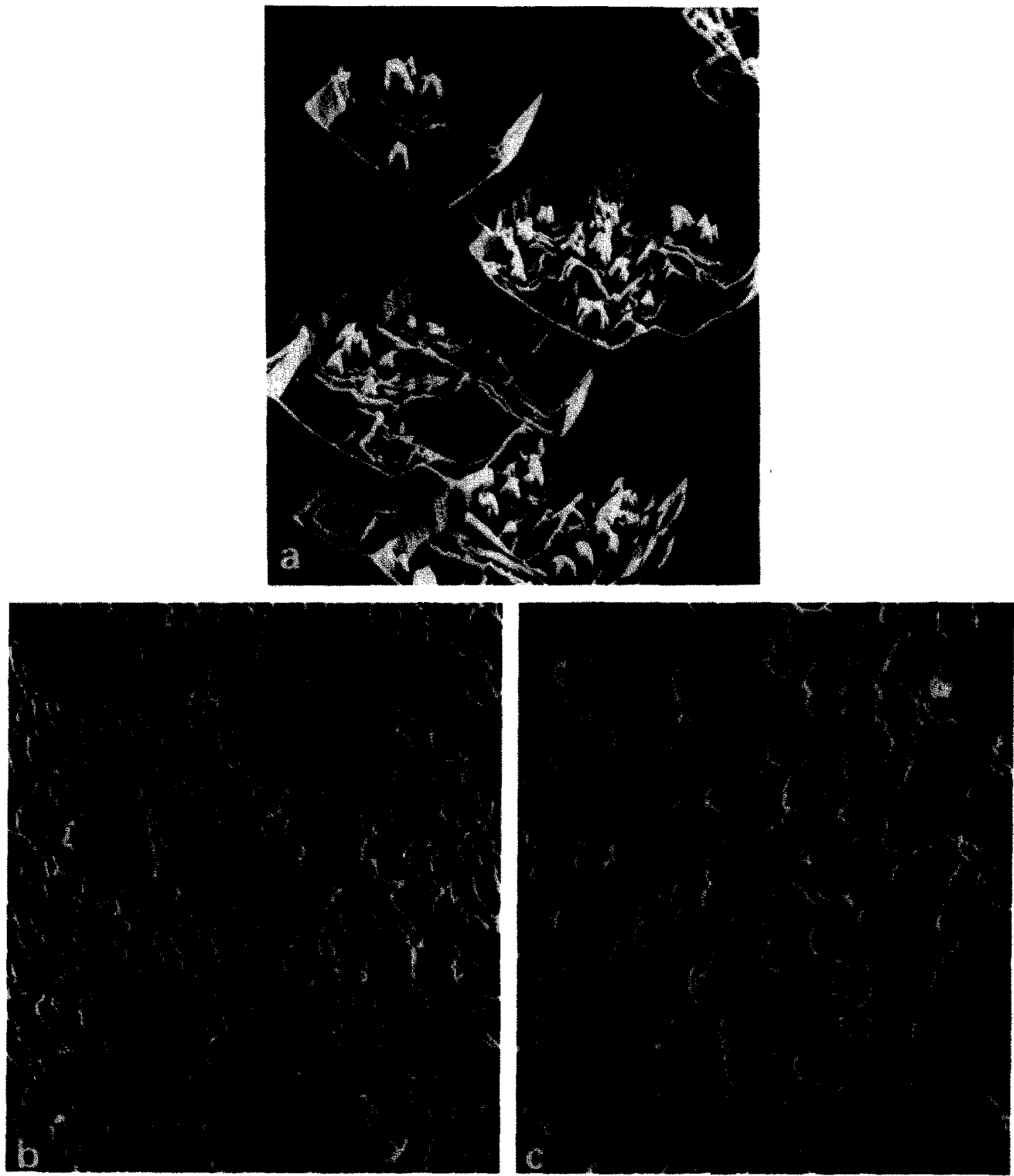

Fig. 4. Scanning electron micrographs showing etch pit features of (a) copper, (b) nickel and (c) Ni-80\% Cu 11131$\rangle$ surfaces after bombardment with $40 \mathrm{keV} \mathrm{Ar}{ }^{+}$to $1 \times 10^{19}$ ions $/ \mathrm{cm}^{2}$ at the high dose rate of $>500 \mu \mathrm{A} / \mathrm{cm}^{2}$. Magnification $1500 \times$.

are shown in fig. 4 . This time it is only the copper that exhibits pyramids, albeit of twisted and bent form similar to those shown in other work [14] where $\mathrm{mA} / \mathrm{cm}^{2}$ currents were used. Only pits are seen on the nickel and nickel alloy and this may well be due to the differences in thermal conductivity, nickel having a factor of about
7 lower thermal conductivity than copper. The net result of this could be a higher implantation-induced temperature and a subsequent more rapid annealing of the ion-induced defects so necessary for the formation of topographical features.

Further surface analytical studies were made on the 
ion-bombarded alloy by EDS and by scanning Auger electron spectroscopy. No evidence of segregation was found. The experimental limits of these techniques for these materials are $\pm 0.5 \mathrm{wt} . \%$

\section{Conclusion}

In summary, we find that very well defined pyramidal features can be formed on an $\langle 1131\rangle \mathrm{Ni}-8 \% \mathrm{Cu}$ alloy at dose rates lower than necessary on the pure metallic components. The reason for this is not clear. Surface analytical studies showed no sign of segregation. Much higher dose rates can produce pyramids on copper but not on nickel nor on the alloy. This is presumably due to large differences in thermal conductivity allowing rapid annealing of the ion-induced defects always assumed to be necessary in the initiation of sputter-induced surface topographical features.

We are grateful to Surface Science Western for the scanning Auger analyses. Financial support from the Natural Sciences and Engineering Council of Canada, the Science and Engineering Research Council, UK and from a NATO Research Grant no. 0122/87 has been instrumental in allowing us to continue this collaboration.

\section{References}

[1] C. Carter, M.J. Nobes, J.L. Whitton, L. Tanović and J.S. Williams, Proc. 7th Int. Conf. on Atomic Collisions in
Solids, Moscow (Moscow State Univ. Publ. House, 1980) p. 69.

[2] J.L. Whitton and G. Carter, Proc. Symp. on Sputtering, eds. P. Varga, G. Betz and F.P. Viehbock (Inst. für Allgemeine Physik, Tech. Univ., Vienna, 1980) p. 552.

[3] G. Carter, M.J. Nobes and J.L. Whitton, Appl. Phys. A38 (1985) 77.

[4] G. Carter, M.J. Nobes, I.V. Katardjiev and J.L. Whitton, J. Mater. Sci. Eng. 90 (1987) 21.

[5] J.L. Whitton, in: Erosion and Growth of Solids Stimulated by Atom and Ion Beams, Proc. NATO ASI Series E112, eds. G. Kirkiakidis, G. Carter and J.L. Whitton (Martinus Nijhoff, Dordrecht, 1986) p. 151.

[6] G.F. Wehner, J. Vac. Sci. Technol. A3 (1985) 1821.

[7] S.M. Rossnagel, in: Erosion and Growth of Solids Stimulated by Atom and Ion Beams, Proc. NATO ASI Series E112, eds. G. Kiriakidis, G. Carter and J.L. Whitton (Martinus Nijhoff, Dordrecht, 1986) p. 181.

[8] O. Auciello, J. Vac. Sci. Technol. 19 (1981) 841.

[9] J.L. Whitton, L. Tanović and J.S. Williams, Appl. Surf. Sci. 1 (1978) 408.

[10] T. Tanovic, J.L. Whitton and S. Kofod, Physics of Ionized Gases, ed. R. Janev (Institute of Physics, Belgrade, 1978).

[11] J.L. Whitton, G. Kiriakidis, G. Carter, G.W. Lewis and M.J. Nobes, Nucl. Instr. and Meth. B2 (1984) 640.

[12] G. Carter, M.J. Nobes, I.V. Katardjiev, J.L. Whitton and G. Kiriakidis, Nucl. Instr. and Meth. B18 (1987) 529.

[13] J.L. Whitton, L. Clapham, G. Carter, I. Katardjiev, M.J. Nobes and G. Kiriakidis, 14th Symp. on The Physics of Ionized Gases Sarajevo, Yugoslavia, eds. L. and N. Tanovic (1988) to be published.

[14] R.S. Gvosdover, V.M. Efremenkova, L. Bshelyakin and V.E. Yurasova, Radiat. Eff. 27 (1976) 237. 